November - 2005

\title{
Distance Higher Education Experiences of Arab Gulf Students in the United States: A cultural perspective
}

\author{
Aisha S. Al-Harthi \\ Sultan Qaboos University, Oman
}

\begin{abstract}
This article reports on a phenomenological research study that was undertaken to provide cultural understanding about the nature of distance education experiences of Arab graduate students pursuing degree programs in the United States. As a theoretical framework, Hofstede's international difference dimensions and Hall's concept of low and high context cultures were used. Six participants were interviewed from the Arab Gulf States. Analysis of these interviews revealed cultural aspects related to student background. Description of participant experiences are explained in the following themes: mandatory nature of the experience, persistence of social shame feelings online, language difficulties, less participation, and avoidance of confrontation and aggravation of feelings. This study concludes with a few recommendations for future research.
\end{abstract}

Keywords: Arab students; culture; distance education; anxiety; online; gender

\section{Introduction}

With the expansion of distance education through the Internet, the World Wide Web, and interactive software, the opportunity to interact with people from different cultures is promising (Hanna, 2000). A number of authors including Gibson, Mason, and Gunawardena et. al. in the Handbook of Distance Education (Moore and Anderson, 2003) refer to the lack of research studies focusing on the cultural aspect of distance education (DE). They foresee opportunity to undertake such studies to provide practical guidelines for global courses and to bring more understanding on cross-cultural differences influencing online students. To contribute to the line of research examining the role of culture in distance education environments, this article reports on a qualitative research study aimed to answer the following questions:

1. How do graduate students from the Arab Gulf region describe their experiences of taking distance education courses during their study in US universities?

2. How do they explain the role of their culture in their distance education experiences? 


\section{Cultural Differences}

For the purpose of this study, culture is defined as in the Dictionary of Concepts in Cultural Anthropology (Winthrop, 1991): "The distinctive pattern of thought, action and value that characterize the members of a society or social group” (p. 50). Being specific to a group, culture is a collectively learned phenomenon. Therefore, it should be distinguished from human nature, which is inherited and universal, and from an individual's personality, which can be inherited or learned and is mainly specific to individuals instead of groups (Hofstede, 1991). To view cultural differences among individuals in distance education, Hofstede's international cultural dimensions and Hall's high- and low-context culture are useful frameworks (Chute and Shatzer, 1995; Wilson, Gunawardena, and Nolla, 2000). Hofstede proposed the following four international cultural dimensions after conducting an empirical study of an international corporation in 50 countries around the world:

1. Small/large power distance. This reflects the range of responses of various countries to social equality and class differences. It determines access and opportunity to society benefits. This may be reflected in the variations in accepting power holders' privileges and lack of access to superiors.

2. High/ low uncertainty avoidance. This explains the degree to which a society can deal with ambiguity and tolerance for deviation from the norm. For example, in a society with high uncertainty avoidance, instructional design must be organized and clearly articulated through upfront detailed description of course processes, activities, and expectations because formal rules of order provide greater stability.

3. Individualism vs. Collectivism. Individualism pertains to societies, such the American society, in which the ties between individuals are loose and everyone is expected to look after himself or herself and his or her immediate family. On the other hand, collectivism pertains to societies such the Arab society, in which people from birth onwards are integrated into strong, cohesive ingroups. A lifetime of protection is exchanged for unquestionable reality. For example, despite the high gender disparity in Saudi Arabia, Jandt (2004) explains how most Saudi women are willing to accept the position of women in return for the guarantee of security that social and Islamic traditions provide for them; even those who seek change want that to occur within the context of the Arab culture.

4. Masculinity vs. Femininity. These are relative terms, meaning a man can behave in a 'feminine' way and a woman can behave in a 'masculine' way. While feminine cultures favor interdependence and service, masculine cultures reflect more materialism, and self-centeredness. In feminine societies, excellence is something one keeps to oneself privileging more modesty and sympathy, whereas masculine cultures appreciate assertive behavior and attempts at excelling (Hofstede, 1991; Chute and Ahatzer, 1995).

Another lens to view cultural differences especially in distance education is Hall's (1976) concept of high-context culture (HC) and low-context culture (LC). Because of the high dependence on written communication and lack of verbal cues, distance education represents low-context interaction. Hall (1976) looks at high- and low-context messages as being placed on a continuum, each making one end of the continuum. He states: "Although no culture exists exclusively at one end of the scale, some are high while others are low" (p. 75). So, while in LC cultures the explicit verbal utterance provides most of the meaning, in HC cultures meaning is integrated within the environmental context and is dependent on non-verbal cues. 


\section{Cultural Studies in DE}

Gunawardena, Wilson and Nolla (2003) suggest that research studies and literature discussion of cultural issues in distance education could be divided into three types of studies:

1. Cultural studies investigating the effect of a certain culture on distance education within the same cultural unit such as (Chan, 2002) study of Chinese students at Hong Kong Open University.

2. Intercultural studies investigating cultural issues between individuals who belong to different cultural units, but they are all involved in taking distance education programs from one cultural unit/ country such as studies of indigenous Australians taking distance courses with mainstream Australians (McLoughlin, 1999) and international students studying in Western countries (Smith and Smith, 2000; Tu, 2001). The study presented in this article falls into this category.

3. Cross-cultural studies that provide comparison between individuals from different cultural units taking distance education programs each within their own cultural unit, such as for example (Gunawardena et. al., 2001) study comparing between American and Mexican students each taking distance education programs within their local universities.

\section{Cultural Differences and Learning}

Sanchez and Gunawardena (1998) explain that there is a connection between cultural background, learning styles, and cognitive processing. They compare Western and non-Western world views and their effects on learning. Western world views include competition, individuality, timing and scheduling, dualistic thinking, nuclear family, superiority of their world view, separation of religion from culture, and task orientation. In comparison, non-Western world views include cooperation, collectivity, relativity of time, holistic thinking, extended family, religion as a part of culture, acceptance of other cultures, and social orientation. Western learning style is characterized by field-independent and analytical thinking compared with non-Western leaning style. The authors note these non-Western world views may also be shared by many Euro-American females and minority groups in Western countries.

Some believe distance education corresponds better with the tendencies of some cultures more than others (Venter, 2003 and Anakwe et al., 1999). For example, Anakwe and colleagues (1999) in their study of 424 students from northwestern U.S. universities found that individualistic cultural orientation is more consistent with distance education compared with collectivistic cultural orientation. They explained that "distance education as a technology can evoke different meanings and reactions among individuals with different cultural orientations" (p. 238). This is due to different cultural orientations towards independence and self-reliance. A similar conclusion was reached in Venter's (2001) study of European and Asia Pacific students enrolled in a master program in the United Kingdom Open University. Students from Asia Pacific countries were more concerned with isolation from the instructor, who they referred to as "a figure of authority, the person with 'the answers" (p. 277) whereas European students expressed isolated from other students and missing out on opportunities for discussion and debates. In addition, Asian students struggled more with uncertainty and self-discipline than European students. 


\section{Cultural Differences and Instructional Design}

It is unusual for people of different backgrounds and languages to necessarily share precise meanings and concepts, or to construct them in the same ways. However, Henderson (1996) points out, instructional design approaches reflect "values, ideologies and images that act in interest of particular cultural, class and gendered groups" (p. 87). Ignoring cultural implications when designing distance education courses for students from different cultures could result in the lack of shared meanings. Thus, communication difficulties occur as various cultures respond differently to layout of graphical interface, images, symbols, colors, and sounds (Chen et al., 1999). To design culturally appropriate materials for Indigenous Australians, McLoughlin (1999) emphasizes three factors: "cultural awareness of the target group, instructional design decisions, and the provision of educational flexibility in an online environment” (p. 234).

In addition, the literature refers to Henderson's argument for a multiple cultural model of interactive multimedia instructional design (Collis, 1999; Wild, 1997; McLoughlin, 1999). This model is based on "incorporating multiple cultural perspectives into an eclectic paradigm, so that multiple cultures maintain their identities and can have their respective cultures accommodated" (Collis, 1999, p. 205). Cultures constantly negotiate the unpredictable social consequences of technology on moral, political, cultural and religious values. Accordingly, they either restrict or advance the use of technology. More discussion is needed to determine how such negotiation is done successfully, especially in Muslim cultures (Ghamari-Tabrizi, 2000).

\section{Distance Education in the Arab World}

Distance education has a short history in the Arab world. For many, it has not been visible, even as a back door to higher education. This is quickly changing however, with the escalating need for national higher education. The history of distance education in the Arab World as described in Alsunbul (2002) can be placed in the following categories (Moore and Kearsley, 2003):

1. First generation of distance education using correspondence studies through Arab University of Beirut (during the 1960s). This is still a popular venue to higher education.

2. Second generation distance education using a total system approach by establishing open universities. This began a decade later (during the 1980s) compared with the international development of open universities in the 1970s. The Arab Open University (AOU) of Prince Talal bin Abdul Aziz Al-Soud is one such recent endeavor in the region. AOU is affiliated with the United Kingdom Open University for purposes of licensing of materials, consultancies, accreditation, and validation of its programs. In addition, some Arab countries such as Sudan, Syria, Egypt, and Saudi Arabia use radio and television broadcasting.

3. Third generation distance education that use electronic media is being slowly adopted by the previous open universities as well as traditional universities, which until now mainly use such technologies to supplement face-to-face courses. Examples of such universities are Arab Gulf public universities such as Ziad University, United Arab Emirates; Sultan Qaboos University, Oman; and University of Bahrain, Bahrain.

\section{Context of the Study}

This study focuses only on individuals from a regional block of Arab Gulf States which includes Saudi Arabia, Oman, Qatar, Bahrain, Kuwait, and the United Arab Emirates. Theses states have 
similar cultures: same or similar language(s), religion, history, norms and values. They even "share many similarities in the development of their socio-economic and political structures, so much so that they together constitute a societal type particular to this oil-rich region" (Khalfan and Alkobaisi, 1999, p. 271).

\section{Research Design}

This study used a phenomenological research design to investigate students' experiences in distance education, and how those experiences relate to their cultures. The data of phenomenological studies are "the conscious experience of phenomena, which would include both the acts such as thinking, believing, perceiving - and the things to which these acts are related such as ideas or material objects" (Merriam and Simpson, 1995, p. 91). The reason for collecting data about a lived experience is that it makes us more "experienced" ourselves through being more informed, shaped, or enriched by this experience (Van Manen, 1990, p. 62). Phenomenology can be descriptive presenting a thick description or what a certain experience was like for an individual. It can also be interpretive or hermeneutic giving an interpretation of meaning from a written text. Van Manen uses both to refer to phenomenology, which is the approach followed in this study.

Semi-structured qualitative interviews were used to collect data. In designing these phenomenological interviews, the researcher followed Seidman's (1991) three-interview series. The first interview lays the context of participants' experience. The second allows participants to reconstruct their experience within the context in which it occurs. The third encourages individual participants to reflect on the meaning the experience holds for him/her. Seidman indicates that it is not necessary to do the three interviews separately, especially if the researcher is constrained by time and availability of participants. Therefore, the researcher conducted only one telephone interview with each participant employing the basic concept of the three-interview series.

\section{Research Participants}

The main research criterion is that participants have taken at least one online course or a major component of their face-to-face courses was online. Three approaches were used to identify potential participants. First, cultural attachés of the Embassies of Arab Gulf States in the US were contacted to send a recruitment message to their graduate students about volunteering in this study. Only one cultural attaché responded positively to this request. Of 109 potential participants contacted, only two met the research criterion. The second approach was to identify a number of leading US universities using distance education and conduct an electronic directory search for famous Arabic male and female names. A total of 82 potential participants were contacted through this approach and only two participants met the research criterion. Finally, snowball sampling was used by asking each person interviewed in the research to suggest names of additional people (Mertens, 1997). Two more participants were identified. You can see that from 191 participants, only six took an online course or had a major online component in their face to face courses: three from Oman, two from Saudi Arabia, and one from the United Arab Emirates. Of these, two were females. Three were studying Information Technology and had engaged in approximately three totally online courses using "First Class." The other three were graduate students majoring in education and only had an online component to complement their regular face-to-face classes using "Course Talk," "Course Info," or webpages. After one to two weeks of initial contact, one semi-structured telephone interview was conducted with each participant concentrating on 1) participants experiences; 2) context of their experience; and 3) personal meaning of experiences (Seidman, 1991). 


\section{Limitation and Assumptions}

Since the researcher is the main instrument in qualitative research, qualitative research carries with it a lot of the researcher's perspective (Merriam and Simpson, 1995). Therefore, the researcher finds it important to address a number of assumptions here. The researcher assumes that research participants knew their home culture well, which is not always the case, given their young age and potential lack of involvement in their society due to living abroad for a long time. Please note that participants in this study are highly educated individuals pursuing graduate degrees in another country. Many even did their undergraduate education in the United States or United Kingdom.

Data for this study was collected in 2001. Since then, some aspects related to technology may have changed. In addition, the awareness of educational systems in the Arab Gulf States of the importance of teaching technology skills has dramatically increased. All participants in this study did not gain technology skills during their years of schooling. Today, technology skills are becoming a core subject in school curriculum of Arab States. This is important to highlight given participants' technological difficulties, initial resistance, and lack of awareness of online courses.

\section{Results and Discussion}

Interviews were transcribed and analyzed. The following themes describe some cultural aspects of participants' experiences:

\section{Mandatory Nature of the Experience: Pushed into distance education}

With no exception, distance education was not a first choice for all participants in this study. In fact, one participant was specifically trying to avoid taking distance education courses because of her fear that her cultural attaché would not approve of her taking distance education courses. Research participants referred to their distance courses as either a "must" or a "requirement." Either their educational institution offered a required course only at a distance or an individual instructor included a distance education component to his/ her face-to-face course. These students are not remarkably motivated distance learners. On the contrary, they saw distance education as a difficulty, about which they had no choice but to overcome in order to fulfill a degreerequirement. They had many fears, concerns, and reservations regarding their mandatory distance education experiences. Those who did not know about the distance education component of their courses were "surprised" and "shocked." One participant thought of dropping the course, but he was advised not to do so because this may delay his graduation.

Anxiety and resistance to take distance education courses by participants in this study could be explained through Hofstede's (1991) uncertainty avoidance dimension. His uncertainty avoidance index shows that Arab countries have stronger uncertainty avoidance (score $=68$ ) than the United States (score $=46$ ). This, by definition, means that members of the Arab culture feel more threatened by uncertain or unknown situations than do members of the American culture. This feeling, as Hofstede explains, is expressed through nervous stress, and a need for predictability and need for written or unwritten rules. Many research participants did not know what to expect as they were faced with an unknown situation, in which anything can happen. Their initial reaction was avoiding it. Many were anxious about it. Their uncertainty was the source for such anxiety. It should be noted that these fears and worries about distance education are not unique to students from the Arab Gulf culture. In fact, they might be common among students from other cultures when taking distance education for the first time; however, the tolerance of uncertainty will depend on ones culture. This finding might be helpful in explaining the lack of available 
participants in this research. Only six out of 191 students contacted by the researcher, took distance education courses, and none of those six took it out of choice.

Many participants stated that they had heard about distance education before, but had only a vague idea of what it would be like to study at a distance. Their lack of knowledge about distance education made them anxious about their experiences. Their anxiety level depended on their personal expectations of distance education. For example, one participant was very anxious and even "scared" regarding her distance education at the beginning because she thought distance education meant total dependence on yourself with complete absence of help from the instructor. Another participant, on the other hand, was more relaxed because he thought distance education would be "very easy."

Lack of technical skills was another reason for Arab students to explained as a source of their anxiety. After a certain period of time, participants reached a comfort zone of learning in the new online learning environment. As they became familiar with the new environment, their initial resistance to use new technology and learn in a new environment was slowly reduced with time. Gibson (1998) refers to "adult's perceptions of his or her ability to succeed in the educational environment” (p. 66) as learner's academic self-concept. For learners in this study, their anxiety reduced their academic self-concept, which made them question their abilities to be successful in their distance education experiences.

After completing distance education courses, however, participants reached a greater appreciation and awareness of distance education options. With the exception of one, all said they will take another online class in the future.

\section{Persistence of Shame Culture Online}

Although learners in this study were not anonymous to their peers because real names and, in most cases, an introduction about each person was posted, the lack of physical appearance gave an impression of anonymity. This made both male and female participants feel freer to speak their minds and more able to participate online. In addition, it reduced assumptions associated with race and gender biases. This was particularly relieving for those who do not represent the status quo, such as the participants in this case. Three participants associated this lack of social presence in online courses with a reduced sense of social embarrassment. They felt the courses became "un-scary," and in some respects more comfortable and relaxing than face-to-face courses. It played a role in "face saving," a concept common in collective cultures, which was also reported by Chan (2002) and Tu (2001). Issa, a research participant, explains:

“. . . sometimes when you have nothing to say. You have nothing to say or you can't participate that much, it's kind of embarrassing. You cannot hide yourself . . . Whereas online you feel more comfortable like if you don't have nothing or ah, you just wait to see what others' saying.”

Consequently, this feeling impacted their learning process negatively as they tended to become lazy, postpone assignments, or even not participate at all. For them, the social pressure of electronic interaction was far less than face-to-face interaction as reflected in the following comment:

“It [online class] doesn't scare me .. . I myself tend to get lazy if the thing is not in front of me ... It makes me more relaxed. I don't see myself studying well before the distance education class . . . But, when I go to the [face-to-face] class, 
I want to understand what he's [instructor] saying. After I get out of the class, I go immediately to the lab to practice”.

For Muslim women in a non-Muslim country, looking different is more visible, especially if they wear Hejab, a headscarf used to cover a woman's hair. In their home cultures, women exercise more privacy because of some societal boundaries such as segregated educational systems and gender segregation within work environments. One female participant felt her appearance affected her participation in face-to-face classes. In addition, she feared that what she said was judged by Americans through their "limited" knowledge of her culture and their stereotype of Arabs, which is often portrayed in the American media as 'terrorists.' Because of the absence of physical appearance online, she felt more comfortable to participate. Even male participants agree that distance education would make it easier for Muslim women to participate in educational settings in the Arab Gulf States. They see it as preserving the original idea of gender segregation in Muslim societies.

Beyond this naïve suggestion of using distance education to increase women participation in education, there are deeper cultural issues to be considered. One issue related to the Arab culture is a woman's constant concern of society's perception of her family or family name and honor. Soffan (1980) explains, in Arab society "the woman is the repository of moral deeds in her family, thus she can destroy the honor of the family. She carries her family honor with her even after marriage and she continues to represent her family through modesty" (p. 18). Therefore, she is always restricted by what she can and cannot do, especially in her interaction with men who know her and her family and can therefore affect society's perception of her family.

Alternatively, family honor can be viewed through Hofstede's (1991) concept of 'shame.' Feeling 'ashamed' comes from infringing upon rules of society. Hofstede characterizes collective cultures as "shame cultures." Guilt would be the counterpart characteristic of shame in individualistic cultures. Hofstede states "shame is social; guilt is individual" (p. 60). In the Arab culture, there are social restrictions in the relationship between genders originating not only from religion, but from cultural traditions as well. Therefore, in some Arab societies more than others, Arab women monitor social boundaries in their relationship with fellow colleagues in educational or noneducational settings. A female research participant explains how difficult it was for her to have a man who knew her family in her distance course. She logs off a chat with an instructor and other 'American' colleagues when he logs in. Her concern of his perceptions of her, and subsequently her family, was greater than her belief in her noble motive of learning:

"I've had a guy in one of my classes, and he's like my husband's friend. And whenever he enters the chat, I log off . . . I don't feel comfortable especially a person, who knows us. Knows my husband. I just; I don't feel comfortable. Although I'm there to learn and there to participate, I'm not suppose to do that (laughs). It's very obvious when you log off. It it shows, and when you log in, it shows like the guy saw me log off when he enters the chat, so, and the second time when I entered again he was gone, you know like it's like he felt that I logged off because of him. I don't feel comfortable. I just don't feel comfortable when a guy that knows us is there just I don't know why ... I'll be very nervous talking because I feel somebody is watching me, and probably making assumptions ... I'm trying to avoid you know, but I'm I'm not supposed; I'm not supposed to log off a chat because you know because I'm there.”

Similarly, another male participant mentioned feelings of "shame" when "inappropriate" words, from his cultural perspective, were mentioned in class. However, he felt the situation was not as embarrassing with Americans as it would have been with Arabs. Shame is a collective concept. It 
results from expected social sanctions when cultural norms are broken. Shame persisted in the online environment for those students; however, it was only felt with those who shared the same culture. In the absence of a shared culture, the two participants privileged assumptions and values of Western culture underlying the design and facilitation of material. This reminds us once more that what is taken for granted as an "accepted" view about social structure, political structure, gender, race, ethnicity, age, religion, nation, or profession, may not be considered in the range of acceptable beliefs or customs for a person from a different background (Dorter, 1997).

This persistence of 'shame culture' online is consistent with the empirical evidence from Inglehart and Baker (2000), who analyzed the third wave of the World Value Surveys conducted in 1995-1998. These surveys covered 65 societies representing 75 percent of the world population. The researchers conclude that although values can and do change, "belief systems exhibit remarkable durability and resilience.” Changes brought by economic development and modernization continue to reflect society's cultural heritage be it Protestantism or Confucianism or Islam (p. 49).

\section{Language Difficulties}

For participants in this study, English was a second language and not all participants were at the same level of English proficiency. Participants with low language proficiency had an added difficulty online with the rigorous amount of reading and writing required. One reason was the lack of physical gestures and the total dependence on the written word. Collective cultures depend more on high context messages, while individualistic cultures depend more on low context messages (Hofstede, 1991). This made it "doubly" hard on Arab students who come from a collective culture to participate online in low context messages (Hall, 1976). Lewis (2003) characterizes the communication style of Arabs as multi-active depending heavily on face-to-face communication. One participant felt she lost the "other tools" to explain with. This made online participation more time consuming. One participant reported spending double the time Americans spent on assignments. Another decided not to participate and lose 5 percent of the course grade. In addition, distance education courses move participation from speaking to writing, which is a harder language-productive task than speaking, especially for individuals coming from oral cultures.

On the positive side, online participation had the advantage of providing more structure and rules, which reduced the uncertainty felt by some participants. A research participant with low English proficiency, having the chance to view other classmates' assignments made the "American standard" in writing more visible to him. In addition, the use of what he referred to as "academic language" over colloquial speech made it easier to understand others online compared with faceto-face. For more advanced English learners, time gained in online courses was a major advantage.

\section{Less Participation: Don't appear too eager}

In feminine cultures, students do not want to appear too eager. By contrast, in masculine cultures students try to make themselves visible and compete openly in class. With Arab countries scoring more on the femininity index, Arab students might show such eagerness to participate in class less than American students (Hofstede, 1991). At the beginning of her study in the US, a female participant could not explain Americans eagerness to participate in the classroom. She felt they were "showing off" or trying to appear "smart." She felt that if she wants to talk in class, she must have something important to add. This shows the epistemological difference between 
individualistic societies such as the United States, where the focus is more on learning process compared with collective society where the focus in more on the product.

Participation also relates to the type of power distance between a teacher and student. In small power distance educational environments such as the U.S., students make uninvited interventions and ask clarification questions about the material, whereas in large power distance cultures such the Arab States, teachers initiate all communication (Hofstede, 1991). Students speak only when called upon. Current trends in the educational systems of Arab States encourage student participation in the classroom, while maintaining a level of power distance between students and teachers. In addition, a number of participants preferred communicating at an individual level with the instructors for inquiries instead of posting online for a class forum. This felt easier and more comfortable to do.

\section{Avoiding Confrontation and Aggravation of Feelings}

Because of instructors' role as course editors, who can add and delete course postings as they desire, some research participant felt helpless and frustrated when instructors exercised such power in the online environment without proper explanation. A research participant mentioned how her instructor deleted questions she posted to the online class folder without any explanation or a response for her inquiry about the reason. Similarly, another participant needed a clarification from his instructor on an exam question, and was faced with the same negligence, which consequently affected his grade in the course. In addition, two participants reported the absence of explanation in grade reports. One student explains her struggle:

"I read this course, and I feel that I understood it, and despite this I got C in it. It was the first course I get a $\mathrm{C}$ in. What devastates me more now is that I sent him an email. I was trying to be kind of polite . . . I did everything . . . I took my weekly assignment to the people in the library to read to see if I covered the points, and to see if I answered correctly, and they all say "ok, superb”, and at the end I find something like this ..."

Eventually, these participants preferred to suppress their frustration instead of confronting their instructors, and even those who tried to confront their instructor did not persist:

"What else can I do more other than make it big and put an official complain about him, and this nonsense, and I don't want to do that. If we had the professor on campus, I would go to meet him. But this I don't know what more to do other than sending an email.” (emphasis added)

"I misunderstood the question . . . I asked for a clarification, and I didn't get clarification let's say probably it was my fault, but the outcome wasn't as I expected.” (emphasis added)

This lack of response from instructors not only affected their grades, but affected their selfconcept as they started to doubt themselves and their ability to learn. Reasons for such avoidance of conflict with instructors may include keeping their options open for future cooperation (Lewis, 2003). Many research participants knew they will be taking future courses with these instructors. Saving their face and avoiding social embarrassment (Hofstede, 1991) may be another reason. 


\section{Future Research}

Anthropologists believe that various aspects of culture are interrelated. Therefore, if we touch culture in one place, everything else will be affected (Hall, 1976). Studying in the United States, participants in this study certainly had more understanding of U.S. culture and educational system than individuals who have not had the chance of studying abroad. If they were not successful to do so, they would have either reduced their participation in U.S. community or be forced to leave the community (Lauzon, 1999). Therefore, it would be interesting to replicate this study with individuals from the Arab Gulf States taking distance education courses in their home countries within their culturally relevant environment. In this case, cultural issues might be more evident as individuals interact with their cultural reality on a daily basis. This raises questions about potential Western cultural hegemony of distance education. For example, in discussing the effect of communication technology in the United Arab Emirates (UAE), Jones (1996) argues that "in the UAE, the introduction of communication technology has been a more effective means of intellectual colonization than has been achieved under many years of colonial rule” (p. 53). In her opinion, this contact with the West through communication technology made Arabs lose touch with their relevant and more direct social, cultural, and political issues. The question becomes would distance education result in such intellectual colonization and/or acculturation? Or would it provide a richer perspective to view local issues?

It is evident from this study that there are gender differences in the nature of distance education experience between Arab men and women. Norris and Inglehar (2002) report from empirical data that the greatest cultural gap between Western and Islamic societies is not in democratic values as some suggest. Instead, it is in gender equality and sexual liberalization. They explain "as younger generations in the West have gradually become more liberal on these issues, this has generated a growing cultural gap, with Islamic nations remaining the most traditional societies in the world" (p. 3). Although distance education will greatly benefit from general research about gender differences in Muslim societies, more specific research is needed to investigate the implications of gender differences in course design and delivery in order to facilitate the distance education experience for students from these cultures.

\section{Conclusion}

As this study shows, Arab Gulf students were hardly interested in distance education opportunities available for them in the United States. One reason for individuals' resistance was the vague policy towards it at the governmental level in the Arab Gulf States. If Arab Gulf States were to benefit from distance education, they should deal with the resistance at two levels: individual level and governmental level. At the individual level, it is important to promote distance education to Arab Gulf students by providing a clearer and a more detailed picture of distance education. At the governmental level, if Arab Gulf States do not want to find themselves overwhelmed with global distance Western providers, a more proactive approach is required to articulate policies addressing critical issues, such as the ones suggested by Farrell (1999), including equity of access, curriculum relevance to labor market needs, accreditation, consumer protection, and cultural sensitivity.

In conclusion, this study does not aim to make any generalizations about the experience of Arab Gulf students in U.S. distance education; however, it attempts to bring attention to the importance of cultural issues in understanding their experiences. Cultural differences can make inter-cultural communication time consuming, difficult, and sometimes impossible (Lewis, 2003). Therefore, a major requirement for successful expansion of global distance education is to understand cultural 'distance,' "the extents to which different cultures are different or similar" (Shenkar, 2001, p. 
519) so that such cultural multiplicity can be incorporated in the processes of distance education design and delivery.

\section{References}

Alsunbul, A. (2002). Issues relating to distance education in the Arab world. Convergence, 35(1), $59-81$.

Anakwe, U. P., Kessler, E. H., and Christensen, E. W. (1999). Distance learning and cultural diversity: Potential users' perspective. The International Journal of Organizational Analysis, 7(3), 224 - 243.

Chan, B. (2002). A study of the relationship between tutor's personality and teaching effectiveness: Does culture make a difference? International Review of Research in Open and Distance Learning, 3(2). Retrieved October 6, 2005 from: http://www.irrodl.org/content/v3.2/chan.html

Chen, A.-Y., Mashhadi, A., Ang, D., and Harkrider, N. (1999). Cultural issues in the design of technology-enhanced learning systems. British Journal of Educational Technology, 30(3), $217-230$.

Chute, A., and Ahatzer, L. (1995). Designing for international teletraining. Adult Learning, 7(1), $20-22$

Collis, B. (1999). Designing for differences: cultural issues in the design of WWW-based coursesupport sites. British Journal of Educational Technology, 30(3), 201 - 215.

Dorter, L. (1997). Creating the virtual classroom: distance learning with the Internet. New York: John Wiley's \& Sons Inc.

Farrell, G. (1999). The development of virtual education: a global perspective. Vancouver, BC: The Commonwealth of Learning.

Ghamari-Tabrizi, B. (2000). Islam and High-Technology: Global communications and cultural re-inventions. Paper presented at the proceedings of the Technological Education and National Development: Crossroads of the new millennium, Abu Dabi, United Arab Emirates.

Gibson, C. C. (1998). Distance Learners in Higher Education: Institutional responses for quality outcomes. Madison, WI.: Atwood Publishing.

Gunawardena, C., Nolla, A. C., Wilson, P. L., Lopez-Islas, J. R., Ramirez-Angel, N., and Megchum-Alpizar, R. M. (2001). A cross-cultural study of group process and development in online conferences. Distance Education, 22(1), 85 - 121.

Gunawardena, C. N., Wilson, P. L., and Nolla, A. C. (2003). Culture and online education. In M. G. Moore and W. G. Anderson (Eds.) Handbook of Distance Education. Mahwah, NJ.: Lawrence Erlbaum.

Hall, E. (1976). Beyond Culture. New York, NY.: Anchor Press. 
Hanna, D. (Ed.). (2000). Higher Education in an Era of Digital Competition: Choices and challenges. Madison, WI.: Atwood Publishing.

Henderson, L. (1996). Instructional Design of Interactive Multimedia: A cultural critique. Educational Technology Research and Development, 44(4), 85 - 104.

Hofstede, G. (1991). Cultures and Organizations: Software of the mind. London: McGraw-Hill.

Inglehart, R., and Baker, W. (2000). Modernization, cultural change, and the persistence of traditional values. American Sociological Review, 65(1). 19 - 51.

Jandt, F. E. (2004). An Introduction to Intercultural Communication (4th ed.). Thousands Oaks, CA.: Sage.

Jones, A. (1996). Communications, Technology, Human Resource Development and Sociocultural Issues: Considerations for small Gulf countries. Convergence, 29(4), 49 56 .

Khalfan, S., and Alkobaisi, S. (1999). Migrants' Strategies of Coping and Patterns of Accommodation in the Oil-rich Societies: Evident from the UAE. British Journal of Middle Eastern Studies, 26(2), 271 - 299.

Lauzon, A. (1999). Situating Cognition and Crossing Borders: Resisting the hegemony of mediated education. British Journal of Educational Technology, 30(3), 261 - 276.

Lewis, R. D. (2003). The Cultural Imperative: Global trends in the 21st century. Yarmouth, ME.: Intercultural Press.

McLoughlin, C. (1999). Culturally Responsive Technology Use: Developing an on-line community of learners. British Journal of Educational Technology, 30(3), 231 - 143.

Merriam, S., and Simpson, E. (1995). A Guide to Research for Educators and Trainers of Adults (2nd ed.). Malabar, FL.: Krieger.

Merterns, D. M. (1998). Research Methods in Education and Psychology. Thousand Oaks, CA.: Sage.

Moore, M. G., and Anderson, W. G. (2003). Handbook of Distance Education. Mahwah, NJ.: Lawrence Erlbaum.

Norris, P., and Inglehart, R. (2002). Islam \& the West: Testing the clash of civilizations thesis. Cambridge, MA.: John F. Kennedy School of Government, Harvard University.

Sanchez, I., and Gunawardena, C. (1998). Understanding and supporting the culturally diverse distance learner. In C. C. Gibson (Ed.) Distance Learners in Higher Education: Institutional responses for quality outcomes . Madison, WI.: Atwood.

Seidman, I. (1991). Interviewing as Qualitative Research: A guide for researchers in education and the social sciences. New York, NY.: Teachers College Press. 
Smith, S. N., and Smith, P. L. (2000). Implications for Distance Education in the Study Approaches of Different Chinese National Groups. Journal of Distance Education, 15(2), $71-84$.

Shenkar, O. (2001). Cultural Distance Revisited: Towards a more rigorous conceptualization and measurement of cultural differences. Journal of International Business Studies, 23(3), $519-535$.

Soffan, L. (1980). The Women of the United Arab Emirates. New York, NY.: Harper \& Row.

Tu, C. H. (2001). How Chinese perceive Social Presence: An examination of interaction in online learning environment. Education Media International, 38(1), 45 - 60.

VanManen, M. (1990). Researching Human lived Experiences: Human science for an action sensitive pedagogy. New York, NY.: State University of New York Press.

Venter, K. (2001). Coping with Isolation: The role of culture in adult distance learners' use of surrogates. Open Learning, 18(3), 271 - 287.

Wild, M., and Henderson, L. (1997). Contextualizing Learning in the World Wide Web: Accounting for the impact of culture. Education and Information Technologies, 14(2), $179-192$.

Wilson, P. , Gunawardena, C., and Nolla, A. (2000). Cultural factors influencing online interaction and group dynamics. Paper presented at the 16th Annual Conference on Distance Teaching and Learning, August. Madison, WI.

Winthrop, R. (1991). Dictionary of Concepts in Cultural Anthropology (Vol. 11). New York, NY.: Greenwood Press.

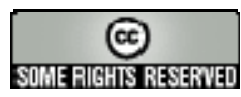

